\title{
¡Humboldt tenía la razón!
}

\author{
Christoph Hirtz \\ Fotógrafo, Quito \\ hirtz_christoph@yahoo.com
}

El Chimborazo es la montaña más alta del mundo. En 1802 el científico alemán Alexander von Humboldt ascendió al coloso hasta una altura de 5.881 metros sobre el nivel del mar y por mucho tiempo fue el récord que un hombre había alcanzado.

Esto lo llevó a afirmar que el Chimborazo era la montaña más alta del mundo. En 1852 se determinó que el Everest es la más alta. Pero considerando que el globo terráqueo es achatado en los polos y ensanchado a lo largo de la línea equinoccial, la posición del Chimborazo con $1,6^{\circ}$ al sur de la línea ecuatorial es privilegiada frente al Everest que se encuentra $28^{\circ}$ al norte. Entonces la distancia desde el centro de la Tierra al Everest es de 6.382.478 metros $y$ al Chimborazo es de 6.384.673 metros, lo que nos da una altura mayor de 2.195 metros. ¡Humboldt tiene la razón!

Todo depende de cómo se mida o se mire. A nosotros los fotógrafos, como a todos los artistas, nos impresiona el Chimborazo y lo plasmamos en nuestras imágenes con la espectacularidad que se nos presenta: alto, majestuoso.

¡Aquí cuenta la primera impresión!
Y siempre me ocurre lo mismo, voy por una calle, viajo por una carretera, o camino por el campo y de repente ahí está, la montaña, en su máxima expresión y mientras avanzo parece que la altura disminuyera, la montaña se desvanece en la cordillera entre los demás picos. Pero nuestra imagen ya expresa lo que sentimos.

Aquí varios ejemplos de cómo diversos artistas ven a nuestro Chimborazo, esta hermosa montaña que es uno de los símbolos de nuestra Patria.

\section{Bibliografía:}

Der Report-Nr.22 Magazin November 1977. 


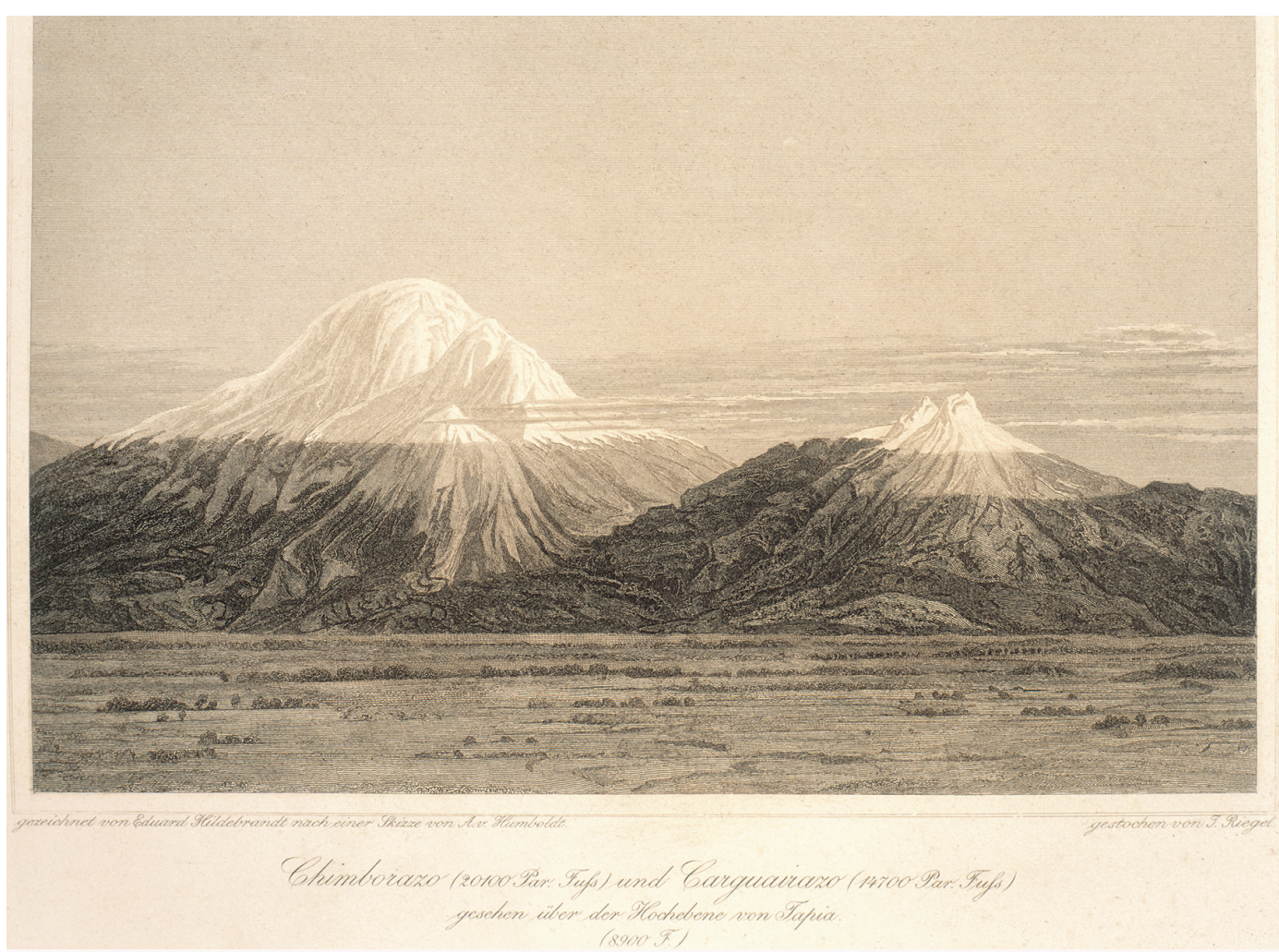

Humboldt Atlas der kleineren Schriften

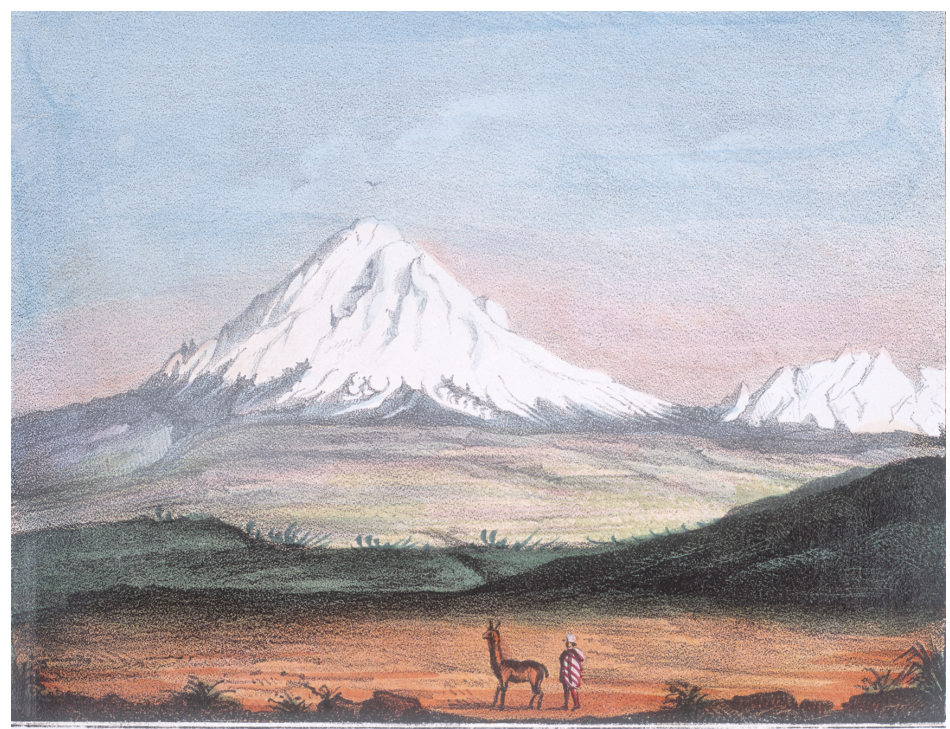

Chimborazo, al Sud. Est di Inito, allezza 214t0. piedt:
Del Viajero italiano Osculati 


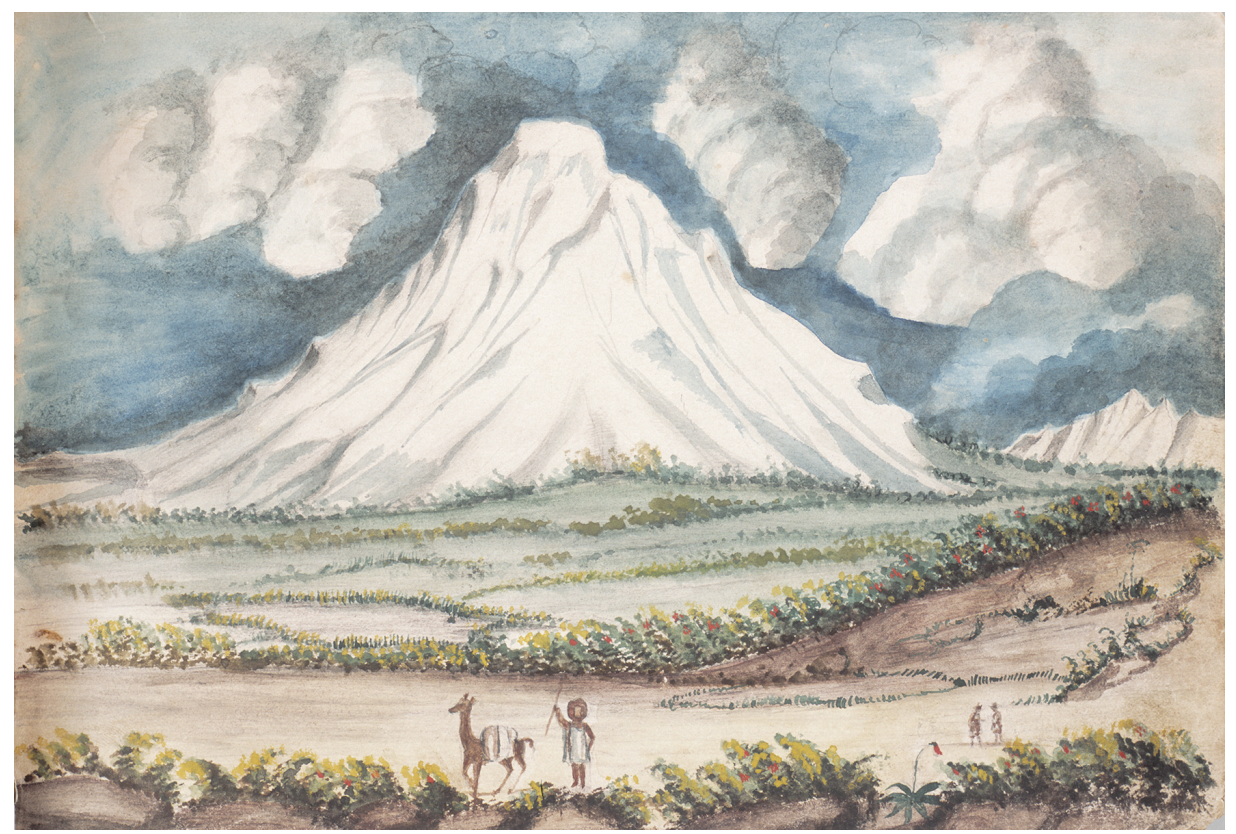

\section{Anónimo}

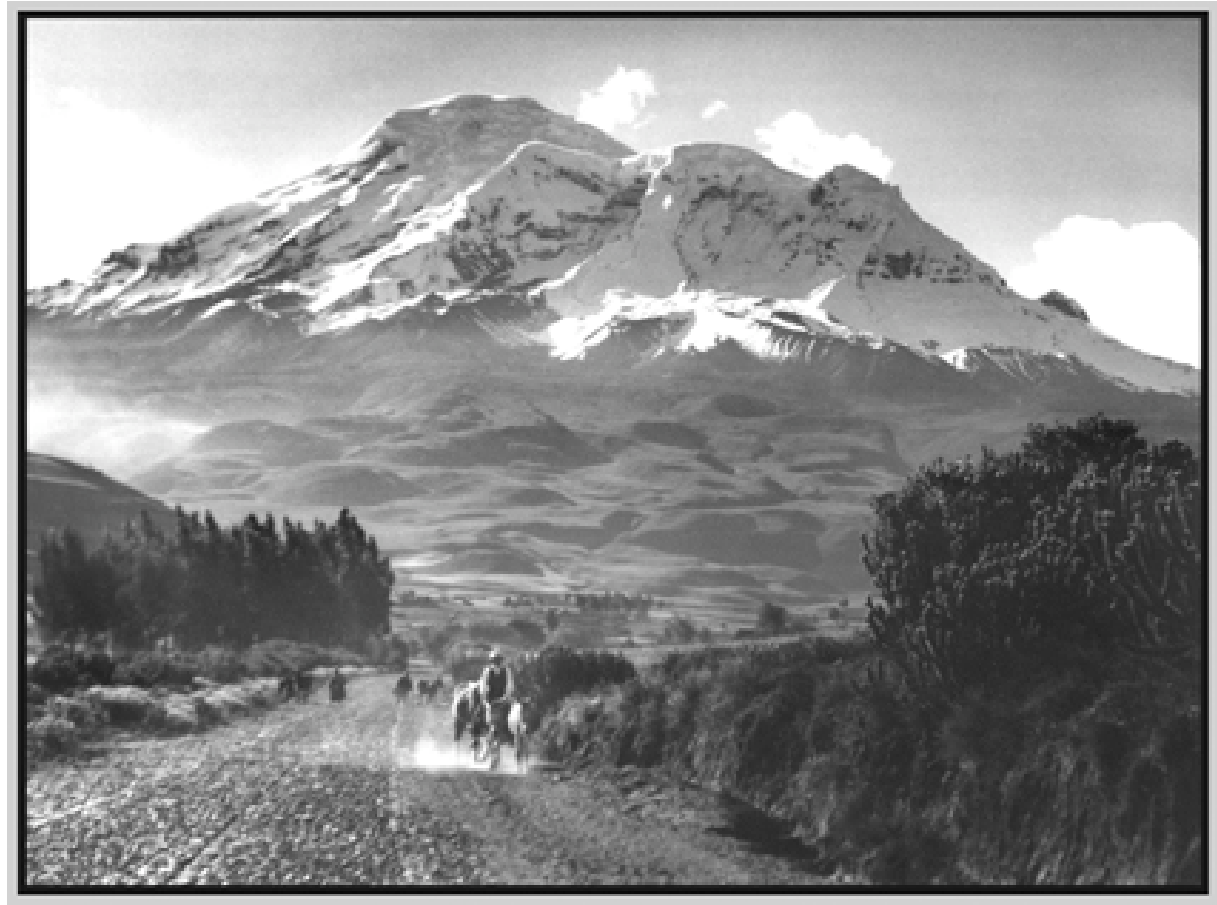

Gottfried Hirtz 1942

Revista Ecuatoriana de Medicina y Ciencias Biológicas - Vol.XXXI Números 1 y 2: 120-123, octubre 2010 


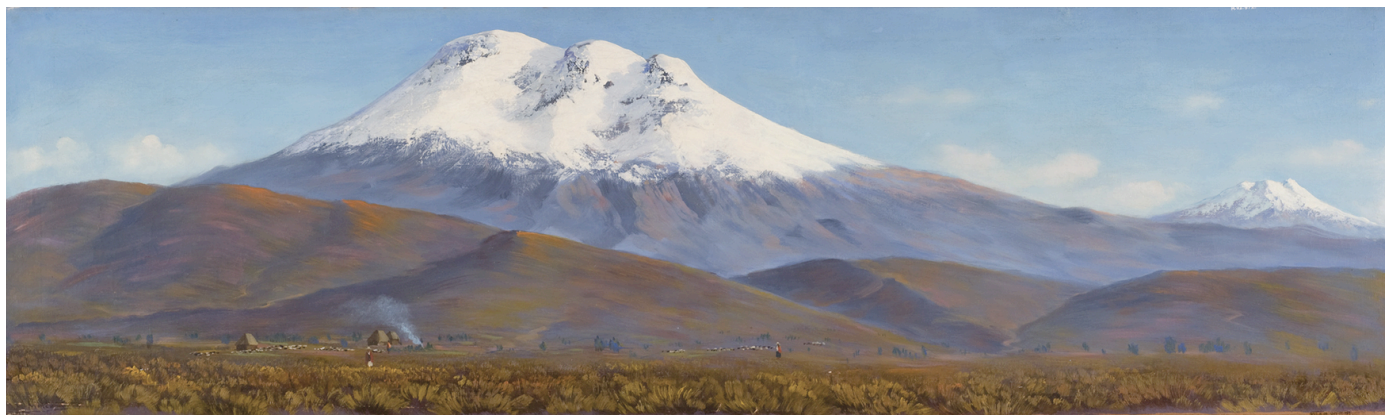

Emilio Moncayo 1940

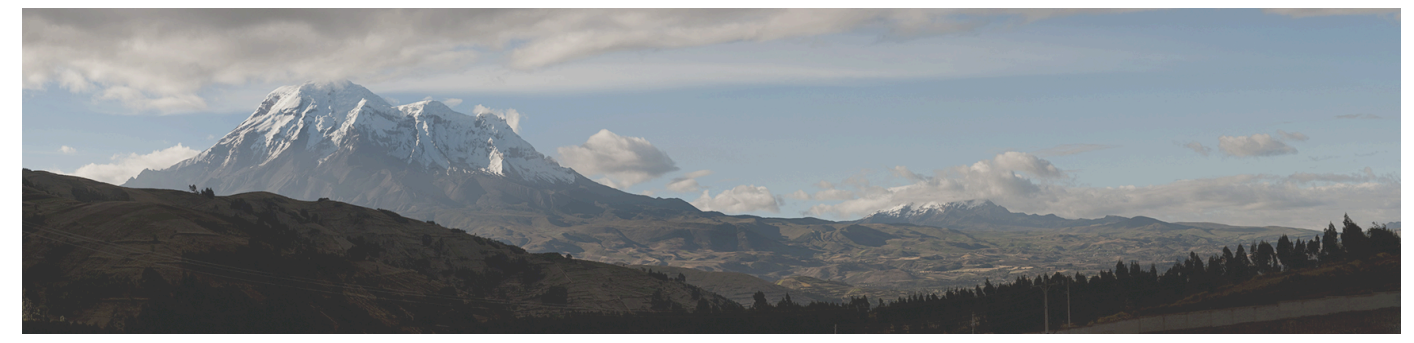

Christoph Hirtz 2010

Revista Ecuatoriana de Medicina y Ciencias Biológicas - Vol. XXXI Números 1 y 2: 120-123, octubre 2010 